\title{
Recent comprehensive review for extended finite element method (XFEM) based on hydraulic fracturing models for unconventional hydrocarbon reservoirs
}

\author{
Belladonna Maulianda ${ }^{1} \cdot$ Cindy Dhevayani Savitri $^{1}{ }^{10} \cdot$ Aruvin Prakasan $^{1} \cdot$ Eziz $^{\text {Atdayev }}{ }^{2} \cdot$ Twon Wai Yan $^{1}$. \\ Yew Kwang Yong ${ }^{1} \cdot$ Khaled Abdalla Elrais $^{1} \cdot$ Reza Barati $^{3}$
}

Received: 22 March 2020 / Accepted: 25 May 2020 / Published online: 8 June 2020

(c) The Author(s) 2020

\begin{abstract}
Hydraulic fracturing has been around for several decades since 1860s. It is one of the methods used to recover unconventional gas reservoirs. Hydraulic fracturing design is a challenging task due to the reservoir heterogeneity, complicated geological setting and in situ stress field. Hence, there are plenty of fracture modelling available to simulate the fracture initiation and propagation. The purpose of this paper is to provide a review on hydraulic fracturing modelling based on current hydraulic fracturing literature. Fundamental theory of hydraulic fracturing modelling is elaborated. Effort is made to cover the analytical and numerical modelling, while focusing on eXtended Finite Element Modelling (XFEM).
\end{abstract}

Keywords Hydraulic fracturing · Unconventional reservoirs · Analytical method · Numerical method $\cdot$ eXtended Finite Element Modelling (XFEM)

\section{Introduction}

According to BP Statistical Review (2017), the global demand for natural gas increased by $1.5 \%$ from 2016 . Therefore, the production of unconventional gas reservoir must be optimized to cover the decreasing of conventional gas reservoir production (Bentley 2002; Hughes 2013). The unconventional gas reservoir is commonly defined as reservoir with poor permeability (less than $0.1 \mathrm{mD}$ ) (Gordon 2012; Holditch 2006). There are four categories of unconventional gas that are becoming important as future source of energy, they are shale gas, tight gas sand, coal bed methane and hydrates (Abdelfattah et al. 2015). Production of unconventional resources is expected to thrive and grow sixfold from 2011 to 2030 (Ruehl and Giljum 2011).

Cindy Dhevayani Savitri

cindy_17006880@utp.edu.my

1 Petroleum Engineering Department, Universiti Teknologi Petronas, Seri Iskandar, Malaysia

2 Civil Engineering Department, University of Calgary, Calgary, Canada

3 Chemical and Petroleum Engineering Department, Kansas University, Lawrence, USA
The shale revolution is referred as the bloom of shale production due to the technological improvement of horizontal drilling and hydraulic fracturing. The improvements include hydraulic fracturing in horizontal well reduced from $200 \mathrm{~m}$ apart to $50 \mathrm{~m}$ while having over 60 stages per well (Aguilera and Ripple 2012; Ignatyev et al. 2011) the USA is the world's largest dry natural gas producer because of the shale gas revolution. It contributes to $20 \%$ of the world consumption, in which $40 \%$ of the supply is from shale (Sieminski 2014). The revolution mainly impacts the USA due to the advancement in technologies in current stage; however, it is expected to spread globally to countries with abundant shale reserves, such as Canada, China and Argentina (Aguilera and Radetzki 2014).

Hydraulic fracturing is a well stimulation method used to improve the permeability of tight gas reservoir for economical production (Britt 2012; King 2012). As the fracture grows, it follows the direction set by in situ stresses in the rock, which can be termed as "fracture direction". The propagation of fracture is perpendicular to plane of least effective stress (Britt 2012; King 2012). Microseismic monitoring is one of the methods to study the characteristics of hydraulic fracturing (Shapiro et al. 2006). Microseismicity is the occurring microearthquakes events caused by the injection of fluid into the borehole (Shapiro et al. 2006). All 
hydraulic fracturing operations stimulated different magnitude of microseismicity. The cloud of microseismic events can be translated into Stimulated Reservoir Volume (SRV), which serves as crucial parameter to study the characterization of reservoir and hydraulic fracturing (Shapiro et al. 2006). Microseismic monitoring is a passive measurement of microseismic event and provides crucial information such as magnitude, location and time of the event (Maulianda 2016). It is proven to be useful in showing the fracture geometries such as fracture length, fracture height, fracture width and fracture azimuth with high confidence (Warpinski and Wolhart 2016). Other application of microseismic monitoring in hydraulic fracturing includes observation of activated natural faults and faults, permeability (Shapiro et al. 1997), and fracturing characterization using Moment Tensor Inversion (MTI) (Nolen-Hoeksema and Ruff 2001).

Stimulated reservoir volume is defined as a collection of fluid-induced microseismic events that reflects the volume of fracture network created in the reservoir (Mayerhofer et al. 2010). Stimulated Reservoir Volume (SRV) was introduced to act as a correlation parameter for well performance (Mayerhofer et al. 2010). SRV compromised by a complex fracture network with different geometries ranging from curved, planar, slanted and of different lengths (Vera and Shadravan 2015). In horizontal well, SRV and fracture network size can be improved with longer lateral lengths and increasing stages of simulation. The study of SRV characteristics optimizes the hydraulic fracturing design. Analytical modelling and numerical modelling are used for SRV modelling.

\section{Other uses of hydraulic fracturing}

\section{Enhanced geothermal system (EGS)}

Geothermal energy is the energy stored within the Earth's crust and it is one of the promising clean renewable energy resources (MIT 2006; Vik et al. 2018). In 2016, it was estimated that only $6-7 \%$ of its total global potential had been extracted (GEA 2016; Vik et al. 2018). The common challenge to exploit geothermal reservoir is the low permeability of the reservoir. To enhance permeability, hydraulic fracturing is performed.

Enhanced Geothermal System (EGS) or Hot Dry Rock (HDR) geothermal system as formerly known was pioneered at Los Alamos National Laboratory, New Mexico, USA in the 1970s (Barbier 2002; Xia et al. 2017). In EGS, a pair of wells are drilled to a depth where rock temperatures approach 300C (White et al. 2017). The wells are then hydraulically fractured, thus creating a connection between the wells. Fluid such a brines, compressed $\mathrm{CO}_{2}$ or liquid mixtures are then circulated from one well to the other in a closed system through the created hydraulic connection. At ambient surface pressure, the heated fluid converts to steam which subsequently drives a turbine to produce electricity. In another method, the heated fluid exchanges heat with a working fluid, which will turn into vapour during the heat exchange process and it will drive the turbine. The cooled fluids are then re-injected into the thermal reservoir or cooled further in a secondary recovery system (White et al. 2017).

To improve heat extraction from geothermal reservoir with low permeability, multiple-induced fractures are created to establish multiple flow paths between the injection well and production well, and to create multiple contact surfaces for heat exchange between hot rock and cold fluid (Bataille et al. 2006; Vik et al. 2018).

\section{Block cave mining}

Hydraulic fracturing started to be applied in mining industry only in recent decades. The application initially was for methane extraction in coal mining in the 1970s in the USA and to control hard roof rockburst (He et al. 2015). Following that, it was applied in cave mining.

Block Cave Mining refers to a method of underground mass mining method in which ore extraction relies on gravity action (Adams and Rowe 2013). The method to induce caving involves undercutting of block by the means of blasting it in order to destroy its ability to support the overlying rock. Gravity then acts to fracture the block (Eklind et al. 2007). Pre-conditioning is required in the event there are massive, unfractured ore body to initiate caving and to reduce caving material size. One of the favoured pre-conditioning methods is intensive hydraulic fracturing in boreholes drilled into the ore body (Van and Jeffrey 2000). The hydraulic fracturing pressure can reach up to $10,000 \mathrm{psi}$, and pumped pure water volume in the range of 4000-5000 litres per fracture, however, the figures can be larger based on pump size and pressure response (Adams and Rowe 2013).

Block cave mining objective is to create horizontal radial hydraulic fractures (HFHFs) that are able to propagate across existing vertical or inclined natural fractures, or to create inclines hydraulic fractures in horizontal or sub-horizontal natural fractures dominated region (He et al. 2015).

\section{Geologic carbon sequestration (GCS)}

In geologic carbon sequestration (GCS), large volume of $\mathrm{CO}_{2}$ are injected into deep geological formations to prevent it from releasing to the atmosphere (Fu et al. 2017; Haszeldine 2009; Orr 2009). The targeted storage is typically saline aquifers or depleted hydrocarbon reservoirs which are overlain by caprocks with low permeability. Consideration to be taken in the $\mathrm{CO}_{2}$ storage design is to ensure caprock integrity to prevent $\mathrm{CO}_{2}$ leakage. However, it is known that hydraulic fractures may be initiated and propagated in the 
caprock when injected fluid pressure exceeds the minimum in situ principal stress of the caprock. Fluid flow along open hydraulic fracture is significantly more efficient as compared to fluid flow in porous medium to deliver the fluid to far-field reservoir; hence, the injection through hydraulic fracturing could improve both storage capacity and $\mathrm{CO}_{2}$ injection. The most desirable scenario in GCS is when the hydraulic fracture can be contained within reservoir rock without fracturing the caprock, at injection pressure level lower than the minimum principal stress of the caprock (Fu et al. 2017).

\section{Analytical modelling}

The SRV modelling is of the highest interest in the hydraulic fracturing designs to predict the facture growth in terms of length, height and width (Rahman and Rahman 2010).
The study of SRV behaviour will enable better optimization of the hydraulic fracturing procedures. Analytical modelling of SRV applies simplified mathematical equations to model the fracture propagation within the rocks (Table 1 and Fig. 1). There have been many 2D and 3D models developed to study the fracture propagation under different conditions and assumptions (Table 2).

\section{Two-dimensional models}

The 2D models were developed in the early 1960 s as a simple approach for fracture design of industry requirement (Gidley 1990). The models are Kristinaovic-Geertsma-de Klerk (KGD) model (Geertsma and De Klerk 1969; Zheltov 1955). Perkins-Kem-Nordgren (PKN) model (Nordgren 1972; Perkins and Kern 1961) and Radial model (Abe et al. 1976). The 2D models have been reasonably successful in

Table 1 Summary of the available analytical models (Rahman and Rahman 2010; Xiang 2011)

\section{D models}

\section{Assumptions}

Constant fracture height

Fracture tip is a pointed shape tip

Fracture shape is rectangular

KGD model

$$
\begin{aligned}
& \boldsymbol{L}=0.48\left(\frac{8 G Q^{3}}{(1-V) \boldsymbol{\mu}}\right)^{1 / 6} \cdot \boldsymbol{t}^{2 / 3} \\
& \boldsymbol{W}_{\boldsymbol{o}}=1.32\left(\frac{8(1-v) \boldsymbol{Q}^{3} \boldsymbol{\mu}}{\boldsymbol{G}}\right)^{1 / 6} \cdot \boldsymbol{t}^{1 / 3} \\
& \boldsymbol{P} \boldsymbol{w}=\sigma_{\text {min }}+0.96\left(\frac{2 G^{3} Q \boldsymbol{\mu}}{(1-\boldsymbol{v})^{3} \boldsymbol{L}^{2}}\right)^{1 / 4}
\end{aligned}
$$

\section{Illustration}

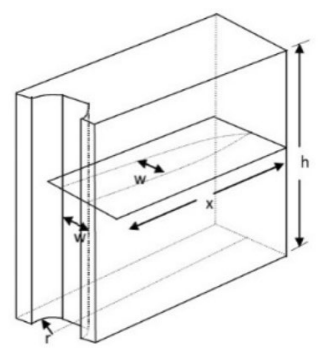

\section{PKN model}

$\boldsymbol{L}=\left(\frac{Q}{\pi c_{l} \boldsymbol{h}}\right) \cdot \boldsymbol{t}^{1 / 2}$

$\boldsymbol{W}_{\boldsymbol{o}}=4\left(\frac{2(1-v) \boldsymbol{Q}^{2} \boldsymbol{\mu}}{\boldsymbol{\pi}^{3} \boldsymbol{G} \boldsymbol{c}_{l} \boldsymbol{h}}\right)^{1 / 4} \cdot \boldsymbol{t}^{1 / 8}$

$P \boldsymbol{w}=2.5\left(\frac{G^{4} Q^{2} \boldsymbol{\mu}}{(1-\boldsymbol{v})^{4} \boldsymbol{h}^{6}}\right)^{1 / 5} \cdot \boldsymbol{t}^{1 / 5}$
Constant fracture height

Fracture toughness does not affect fracture geometry

Fracture shape is elliptical

Fracture is positioned at a plane strain condition in vertical plane

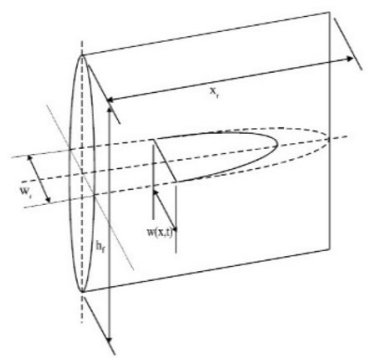

Fracture propagates in each plane Fracture geometry is symmetrical to wellbore Fracture shape is circular

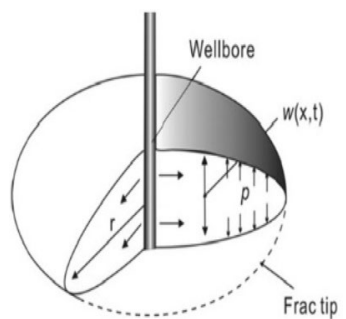

Radial model

$\boldsymbol{\omega}(\boldsymbol{R}, \boldsymbol{\theta})=\frac{4\left(1-\boldsymbol{v}^{2}\right)}{\boldsymbol{E}}[\boldsymbol{G}+\boldsymbol{G} \cos \boldsymbol{\theta}]$

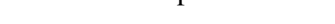




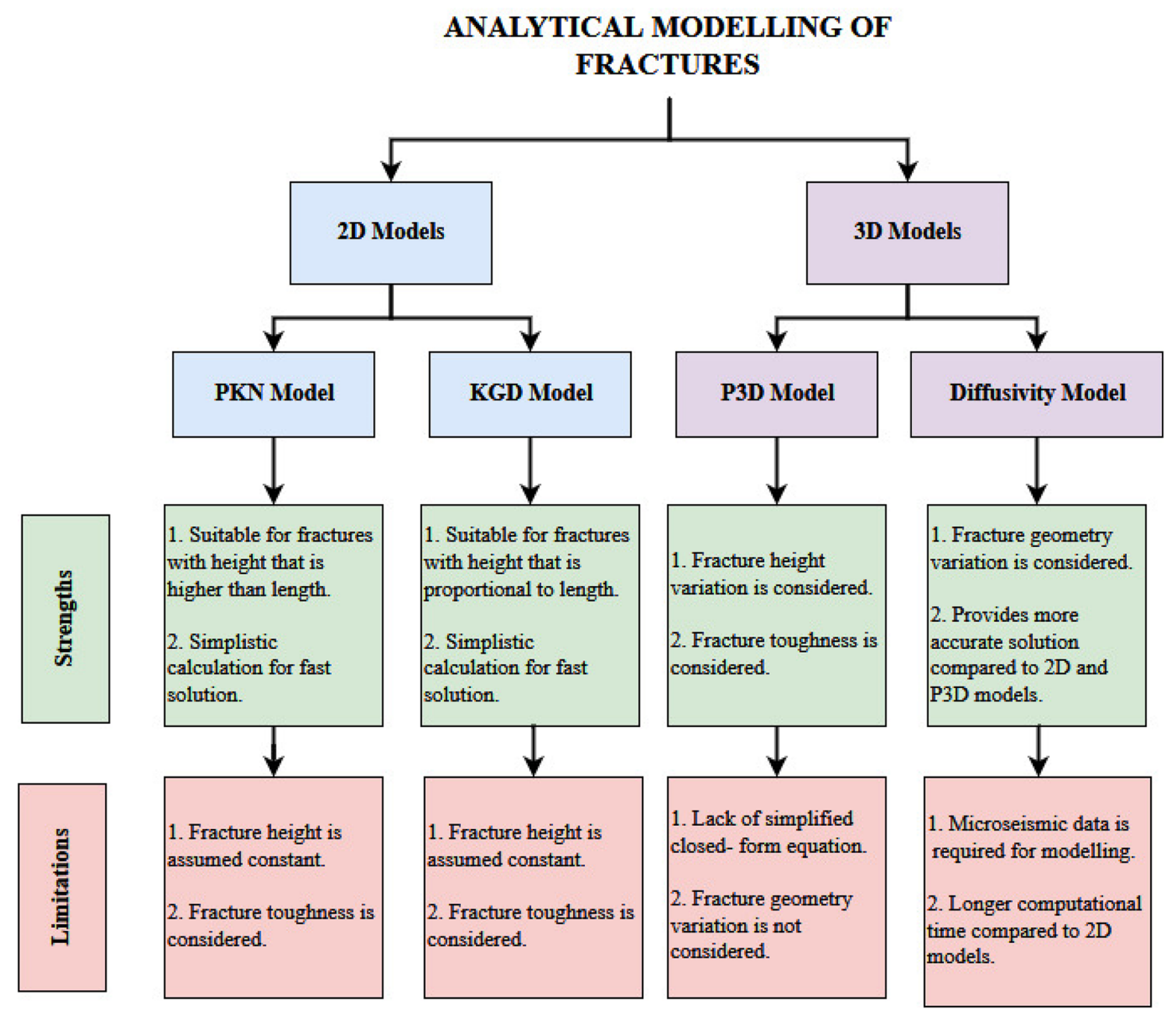

Fig. 1 Comparison of analytical models (Nordgren 1972; Peirce et al. 2010; Perkins and Kern 1961; Settari and Cleary 1984; Simonson et al. 1978; Warpinski and Smith 1989; Yew and Weng 2014; Yousefzadeh et al. 2015; Yu and Aguilera 2012; Zheltov 1955)

practical simulation; however, the assumption of fracture shape and fracture height need to be specified to perform the models limits the practicality of 2D models.

KGD model assumes plane strain in horizontal direction. It represents a fracture with horizontal penetration that is lower than the vertical penetration. The model has cuspshaped fracture tip and the fracture width is uniform in vertical direction. The model is most suitable to be applied for fractures with proportional length-to-height ratio.

In the PKN model, fracture planes are perpendicular to the vertical plane strain. The model has an elliptical-shaped cross section and the fracture toughness is assumed to be not affecting the fracture geometry (Yew and Weng 2014). The pressure is uniform as there is the absence of fluid flow in vertical section. The model is most suitable to be applied for fracture height that is higher than fracture length.

Both 2D constant height models consider fracture width and length as a function of fracture height, treatment parameters and reservoir properties. Vertical fracture propagation is limited by change in material property and minimum horizontal in situ stress (Yousefzadeh et al. 2015). Fracture deformation is linear plastic process in both models. FracCADE is a fracturing design commercial software from Schlumberger for PKN and KGD models.

\section{Three-dimensional models}

The pseudo-3D (P3D) model is proposed to idealize the fracture propagation in multi-layered formations. The constant fracture height assumption is removed in this model (Settari and Cleary 1984; Simonson et al. 1978; Warpinski and Smith 1989). The model is "pseudo" because variation of fracture geometry in three-dimensional space is not considered. The model accounts for height variation by considering the in situ stresses contrast, rock toughness and local net fluid pressure. Some of the commercial softwares available in the market 
Table 2 Summary of researches conducted on studying analytical models (Grechka et al. 2010; Shapiro et al. 1997, 2006; Yousefzadeh et al. 2016; Yu and Aguilera 2012)

\begin{tabular}{|c|c|c|}
\hline Authors & Objectives & Results \\
\hline Shapiro et al. (1997) & $\begin{array}{l}\text { To determine permeability by using diffusivity } \\
\text { model and microseismic events in isotropic } \\
\text { reservoir }\end{array}$ & $\begin{array}{l}\text { Permeability estimation using fluid-induced } \\
\text { seismicity } \\
\text { Good agreement with previous permeability } \\
\text { studies } \\
\text { Unable to be applied in SRV determination due } \\
\text { to assumption of isotropy }\end{array}$ \\
\hline Shapiro et al. (2006) & $\begin{array}{l}\text { To develop nonlinear diffusivity model for } \\
\text { reservoir characterization }\end{array}$ & $\begin{array}{l}\text { Suitable for shale reservoir characterization } \\
\text { using microseismic events }\end{array}$ \\
\hline Grechka et al. (2010) & $\begin{array}{l}\text { To compare and determine permeabilities } \\
\text { using diffusivity model and inversion model }\end{array}$ & $\begin{array}{l}\text { Good agreement of permeabilities obtained } \\
\text { from both models }\end{array}$ \\
\hline Yu and Aguilera (2012) & $\begin{array}{l}\text { To analyse SRV orientation and geometry by } \\
\text { using 3D diffusivity model in anisotrophic } \\
\text { reservoir }\end{array}$ & $\begin{array}{l}\text { Good agreement with microseismic events of } 2 \\
\text { case studies } \\
\text { The method is suitable for other SRVs predic- } \\
\text { tion of similar size } \\
\text { The method is sensitive to spatio-temporal } \\
\text { distribution of microseismic events }\end{array}$ \\
\hline Yousefzadeh et al. (2016) & $\begin{array}{l}\text { To determine and compare the fracture length } \\
\text { from PKN, KGD, P3D and diffusivity model } \\
\text { with microseismic fracture length }\end{array}$ & The diffusivity model is more accurate \\
\hline
\end{tabular}

are FLAC3D by Itasca, FracPro by CARBO and FracMan by Golder (Hou and Zhou 2011).

The most recent development by Yu and Aguilera (2012) is to use mass balance derived 3D model to account for fracture geometry variation. The diffusivity model accounts for the spatio-temporal distribution of fluid-induced seismicity. In their study, the front of microseismic events represents the front of pore pressure diffusion. Hydraulic diffusivity coefficient can be determined from the slope of microseismic events versus time plot. The model can determine fracture geometry under different stimulations case after the determination of hydraulic diffusivity coefficient from three-dimensional microseismic events. Diffusivity model can be solved using MATLAB Partial Differential Equation Toolbox (Peirce et al. 2010).

\section{Diffusivity model}

The 3D model is developed based on linear diffusion equation, for which the approximate solution is shown by Eq. 1 .

$$
\begin{aligned}
\frac{\Delta P_{\text {res }}}{\Delta P_{\text {inj }}} & =\frac{P(x, y, t)-P_{i}}{P_{\text {inj }}-P_{i}} \\
& =\operatorname{erfc}\left(\frac{x}{\sqrt{4 \eta_{x} t}}\right) \operatorname{erfc}\left(\frac{y}{\sqrt{4 \eta_{y} t}}\right) \operatorname{erfc}\left(\frac{z}{\sqrt{4 \eta_{z} t}}\right)
\end{aligned}
$$

Another variation of 3D model based on nonlinear diffusion equation can be summarized as below, where it is derived from continuity equation and Darcy law.
Equation 2 shows the equation derived from continuity equation and Darcy law with the incorporation of real gas equation and formation compressibility equation.

$\frac{\partial}{\partial x}\left(\frac{k p}{2 \mu z} \frac{\partial}{\partial x}\left(P^{2}\right)\right)=\frac{1}{0.000264} \varphi \mu c_{t} \frac{1}{2 \mu z} \frac{\partial}{\partial t}\left(P^{2}\right)$

$u=\frac{p^{2}}{\mu z}$

$P=\sqrt{u \mu z}$

$\frac{\mathrm{d} p}{\mathrm{~d} x}=\sqrt{\mu z} \frac{1}{2} u^{-\frac{1}{2}} \frac{\mathrm{d} u}{\mathrm{~d} x}$

$\frac{\mathrm{d} p}{\mathrm{~d} y}=\sqrt{\mu z} \frac{1}{2} u^{-\frac{1}{2}} \frac{\mathrm{d} u}{\mathrm{~d} y}$

$\frac{\partial}{\partial x}\left(k_{x} \frac{\partial u}{\partial x}\right)+\frac{\partial}{\partial y}\left(k_{y} \frac{\partial u}{\partial y}\right)=\frac{\varphi \mu c_{t}}{0.000264} \frac{\mathrm{d} u}{\mathrm{~d} t}$

The porosity as a function of pressure is defined below (Abe et al. 1976).

$\varphi=\varphi_{i}\left(1-c_{t}\left(P_{0}-P\right)\right)$

The permeability as a function of porosity and specific surface is based on the Kozeny-Carman equation is defined 


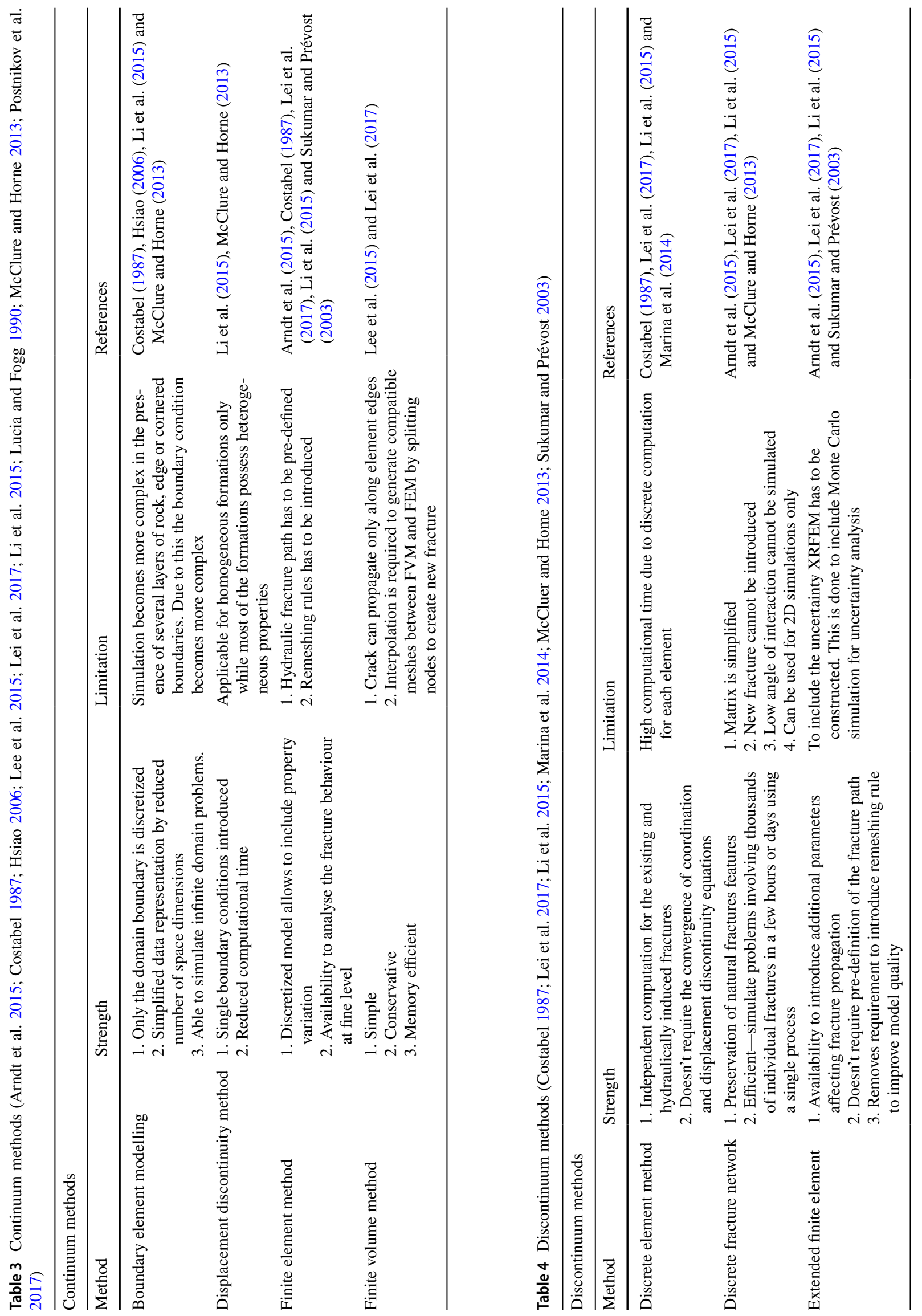


Fig. 2 Heaviside enrichment function (Youn 2016)

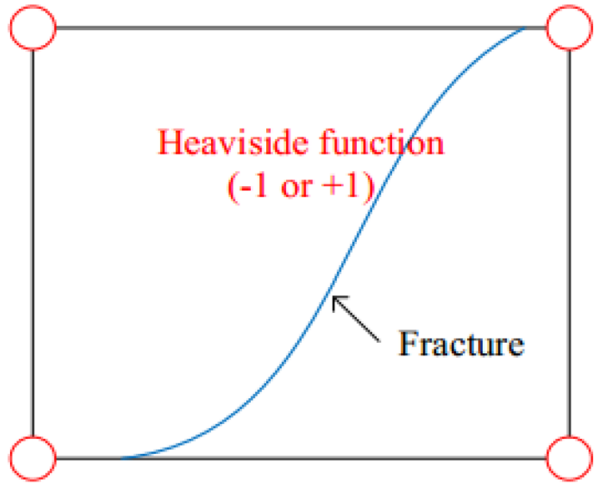

i) Element divided bv fracture

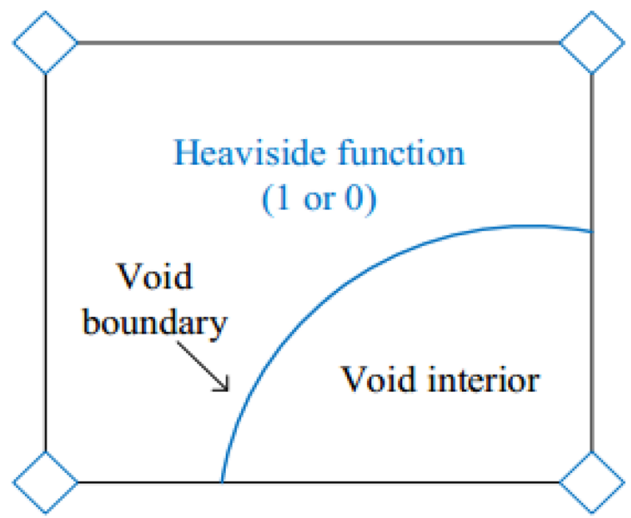

ii) Element divided bv void

Fig. 3 Junction function and branch function (Youn 2016)

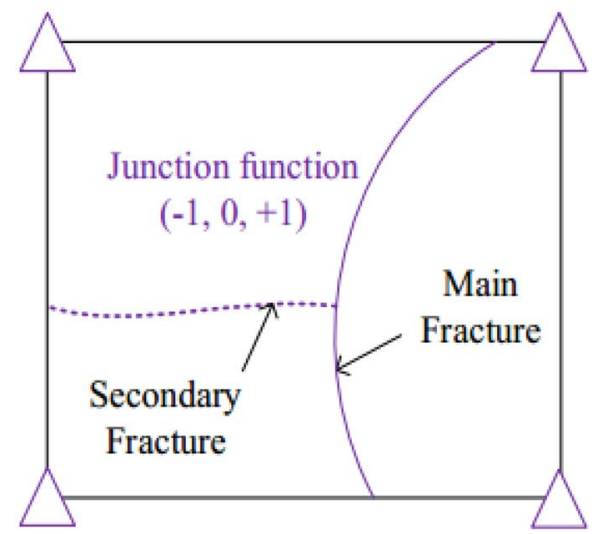

i) Element divided by two

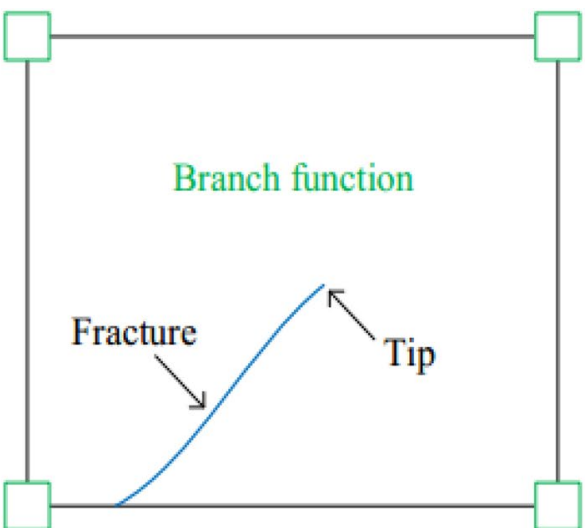

ii) Element containing fracture below (Gates 2011). Rearranging the equation leads to permeability as a function of pressure.

$k=\frac{\varphi_{i}\left(1-c_{t}\left(P_{0}-P\right)\right)^{3}}{5 s^{2}\left(1-\left(\varphi_{i}\left(1-c_{t}\left(P_{0}-P\right)\right)\right)\right)^{2}} 10^{15}$

\section{Numerical models}

Modelling and analysis of hydraulic fractures propagation and interaction have gained enormous interest in petroleum engineering area. Hydraulic fracturing is one of the key important drivers in the development of unconventional reservoirs. Hydraulic fracturing demand has increased rapidly. Modelling tools have been developed to estimate the hydraulic fracturing performance in the formation.

\section{Commonly used numerical models}

Numerical simulation is the incorporation of the analytical solution to identify the behaviour of the events in the presence of more constituents in the system. There are several types of the models available to assess the hydraulic fracture propagation which are divided into two major groups, continuum method and discontinuum method.

Continuum method implies that the matter on which fracture to be simulated is continuous. The pre-existing fractures and stress distribution can be introduced within the continuity and no necessity to introduce the interaction of the boundaries. This method provided the stress distribution at arbitrary location of the fractures and fracture propagation is deduced based on the stress values obtained. However, this method may not show exact behaviour of the fractures. The summary of strength and limitation of the continuum method can be seen on Table 3 .

Discontinuum method on the other hand does show the fracture as separate entity which is introduced as boundary or stress computation limit. These methods give the advantage in simulating the cases with high frequency of cohesive 
elements within the formation. The summary of strength and limitation of the discontinuum method can be seen on Table 4.

The summary of the methods based on the research conducted by several authors (Arndt et al. 2015; Costable 1987; Hsiao 2006; Lee et al. 2015; Lei et al. 2017; Li et al. 2015; Lucia and Fogg 1990; Mcclure and Horne 2013; Postnikov et al. 2017) and (Costable 1987; Lei et al. 2017; Li et al. 2015; Marina et al. 2014; Mcclure and Horne 2013; Sukumar and Prévost 2003) is provided in the diagram below.

\section{Extended finite element modelling (XFEM)}

XFEM is based on the introduction of the enrichment functions on the previously successfully implemented FEM where it is used to simulate the interaction of solid and liquid during injection of fracturing fluid (Maulianda 2016). The enrichment functions allow the fracture propagation simulation to be computed without the necessity to introduce new meshes. The general form of XFEM is as given in Eq. 10 below (Youn 2016).

$u(x)=\sum_{i=1}^{N} N_{i}(x) \bar{u}_{i}+\sum_{j=1}^{M_{1}} N_{j}(x) f_{1}^{\mathrm{enr}} \bar{a}_{j}+\sum_{k=1}^{M_{2}} N_{k}(x) f_{2}^{\mathrm{enr}} \bar{b}_{k}+\sum_{l=1}^{M_{3}} N_{l}(x) f_{3}^{\mathrm{enr}} \bar{c}_{l}$

where $M_{1}, M_{2}$ and $M_{3}$ are different nodes of enrichment, $f_{1}^{\text {enr }}, f_{2}^{\text {enr }}$ and $f_{3}^{\text {enr }}$ are enrichment functions, $N_{i}, N_{j}, N_{k}$ and $N_{l}$ are finite element shape functions and $\bar{a}_{j}, \bar{b}_{k}$ and $\bar{c}_{k}$ are the degrees of freedom.

The enrichment functions introduced in XFEM are Heaviside and Branch enrichment functions. Heaviside function is derived based on the solutions of the level set function (LSF). LSF defines the fracture location and the fracture tip location. Heaviside function is used to

\section{Sign distance function.}

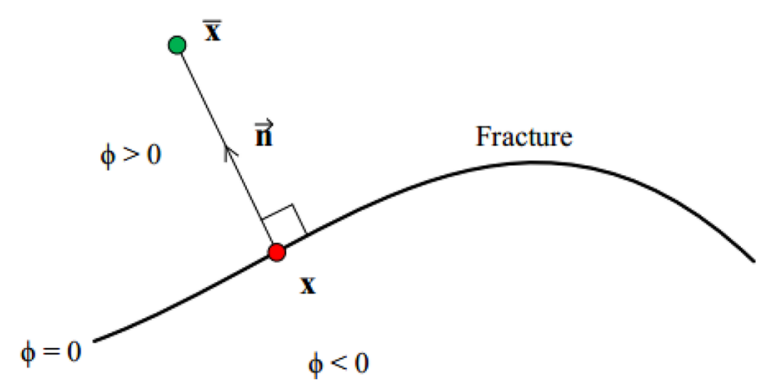

determine the fracture behaviour separating two elements or elements being separated by void (Fig. 2) (Youn 2016).

For the cases with the interaction of two fractures or interaction of fracture with void junction function is implemented. Junction function also uses the LSF to define the fracture location while including the factor which accounts for the secondary fracture.

The Branch enrichment function is applied to identify the behaviour of the fracture tip within the element (Fig. 3).

By incorporating the Heaviside, Branch and Junction enrichment function on the GFEM function Eq. 11 is produced.

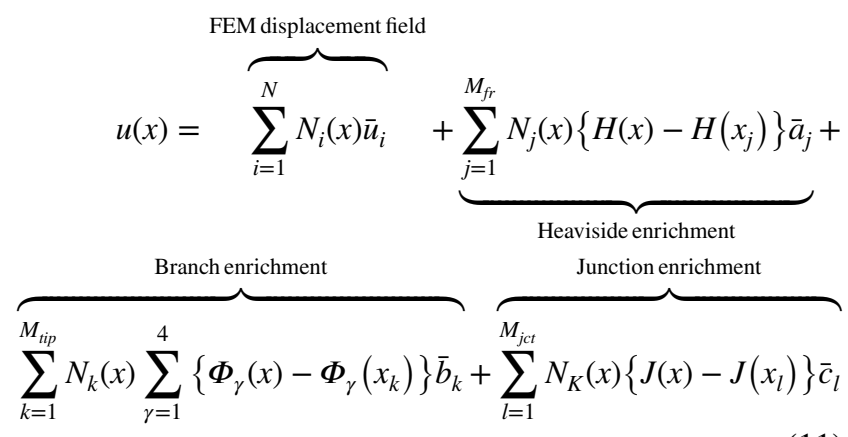

where $H(x)-H\left(x_{j}\right)$, Heaviside enrichment, $\sum_{y=1}^{4}\left\{\Phi_{\gamma}(x)-\Phi_{\gamma}\left(x_{k}\right)\right\}$, branch enrichment and $J(x)-J\left(x_{l}\right)$, junction enrichment.

As the enrichment functions are user defined the XFEM gives a prospect to simulation of the fracture propagation behaviour including any factor required. The necessity is to define the enrichment function in terms of the FEM model composites. As the enrichment is applied on the nodes surrounding the fracture the definition of the equation should be computed based on the node characteristics (Bordas and Moran 2006; Feng and Gray 2017; Sepehri et al. 2015;

Tangential level set.

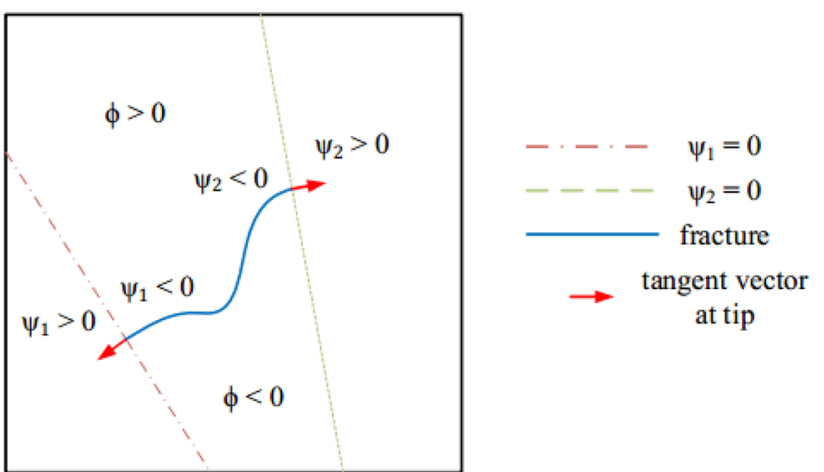

Fig. 4 LSF function parameter visualization (Youn 2016) 


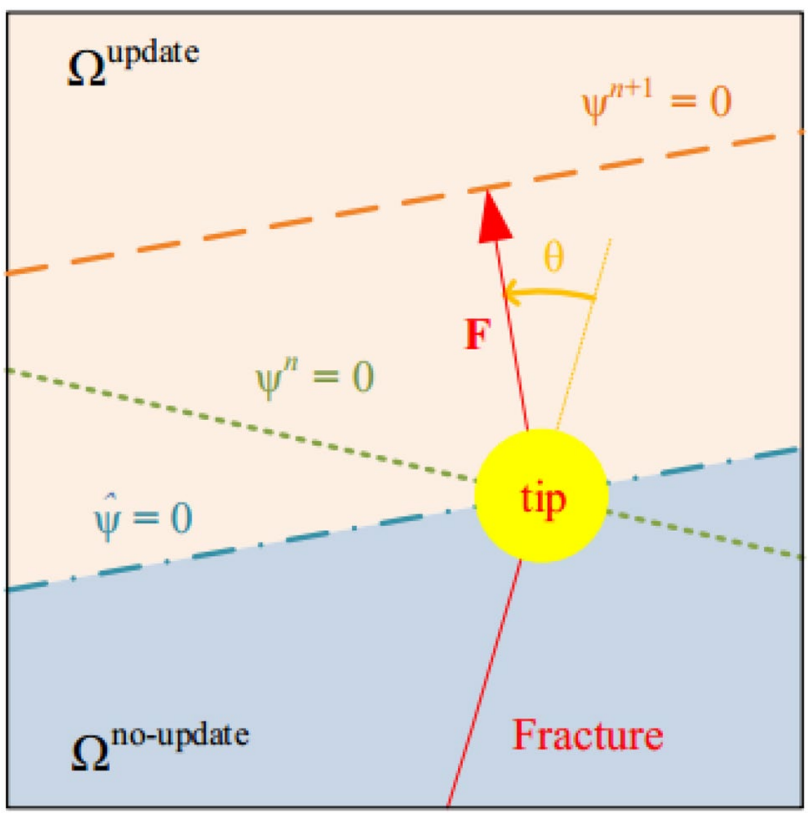

Fig. 5 Identifying the nodes for which LSF is to be updated (Youn 2016)

Youn and Griffiths 2014). Enrichment functions are added into FEM model within the ABAQUS by incorporating the external simulator or built-in python compiler. The latest inclusion into the XFEM is the stochastic simulation of the fracture behaviour. Addition of the random field theory to the currently available XFEM which is also referred as XRFEM allows the simulation of the cases with the inclusion of the uncertainty.

The XRFEM includes Monte Carlo simulation and the average fracture behaviour is computed. This assists in accounting for the uncertainties present within the formation. Modelling of the XFEM in ABAQUS software is similar to FEM. This is due to the XFEM using the FEM as base function. Therefore, the model generation is same as FEM until interaction assignment.

Level set function LSF function defines the output to be used in XFEM node enrichment based on the fracture geometry and spatial location. Two-level set function, sign distance function and tangential level set functions are used to identify the distance of the fracture and fracture tip location (Youn 2016).

The distance of the node from the fracture in Eq. 12 is defined as a multiple of the normal from the fracture which is visualized in Fig. 4. The location of the fracture tip is defined as a function of fracture location and tangent unit vector of fracture as shown in Eq. 12 (Youn 2016).

$\varphi(\mathbf{x})=\operatorname{sign}\{\mathbf{n} \cdot(\mathbf{x}-\overline{\mathbf{x}})\} \min \mathbf{x}-\overline{\mathbf{x}}$ where $\mathrm{x}$ is the nodal point, $\bar{x}$ is the normal projection of the point $\mathrm{x}$ onto the fracture and $\mathrm{n}$ is the unit normal from the fracture at $\bar{x}$.

$\Psi_{\mathrm{i}}(\mathbf{x})=\left(\mathbf{x}-\mathbf{x}_{\mathbf{i}}\right) \cdot \hat{t}_{i}$

where $\hat{t}_{i}$ is the unit vector tangent to the fracture at its tip and $x_{i}$ is the location of the $i$ th fracture tip.

Due to the dynamicity of the fracture propagation behaviour it is also necessary to define the algorithm to locate where LSF update is required.

As the direction of the fracture propagation is based on the stress intensity factor (SIF) as shown in Eq. 14 it is possible to define the LSF update location based on SIF.

$\theta=2 \arctan \frac{1}{4}\left(\frac{K_{\mathrm{I}}}{K_{\mathrm{II}}} \pm \sqrt{\left(\frac{K_{\mathrm{I}}}{K_{\mathrm{II}}}\right)^{2}+8}\right),-\pi<\theta<\pi$

where $\theta$ is the angle of the fracture propagation relative to the existing fracture direction while $K_{\mathrm{I}}$ and $K_{\mathrm{II}}$ are the mode one and two stress intensity factors, respectively.

The domain near the fracture tip is divided into two sections by one planar plane which perpendicular to the fracture tip. Following discretization, the fracture propagation direction is computed based on the stress intensity factors. Then, another perpendicular plane to the unit vector showing the direction of fracture propagation is generated. The LSF parameters are then updated for the nodes behind the newly generated plane (Fig. 5).

Initial stress intensity is defined based on the analytical computation as provided in Eq. 15.

$K_{I}=\sigma \sin ^{2}\left(90-\theta_{f}\right) \sqrt{\frac{\pi L}{2}}$

$K_{I I}=\sigma \sin \left(90-\theta_{f}\right) \cos \left(90-\theta_{f}\right) \sqrt{\frac{\pi L}{2}}$

where $\theta_{\mathrm{f}}$ is the fracture angle relative to the coordinate system and $L$ is the fracture length.

For the dynamic fracture behaviour, the SIFs are derived based on Eq. 17 which is later solved to identify the SIFs for the XFEM model provided in Eqs. 18 and 19.

$G=\frac{K_{\mathrm{I}}^{2}+K_{\mathrm{II}}^{2}}{E_{\mathrm{ff}}}$

where $G$ is the energy release rate and $E_{f f}$ is the effective Young's modulus.

$K_{\mathrm{I}}^{\mathrm{XFEM}}=\frac{I_{I}^{\mathrm{int}} E_{\mathrm{eff}}}{2}$ 
Fig. 6 General steps in XFEM modelling

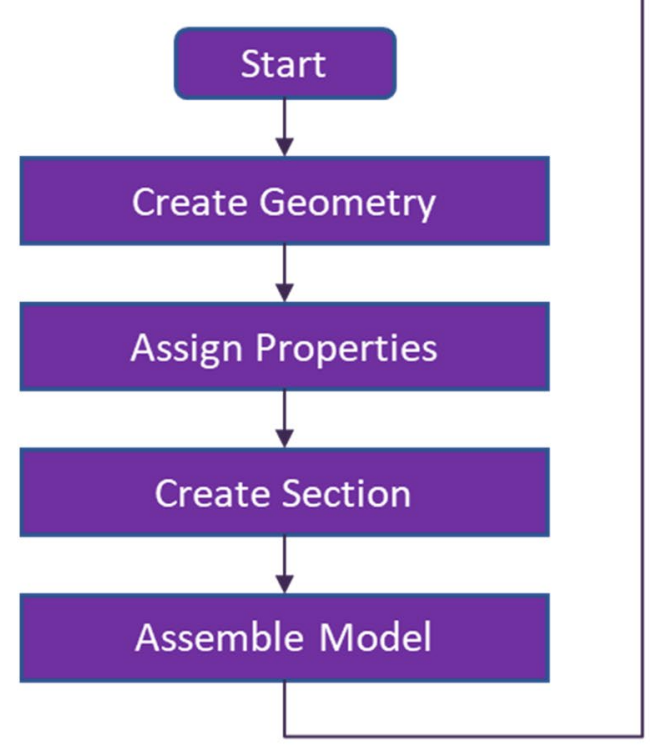

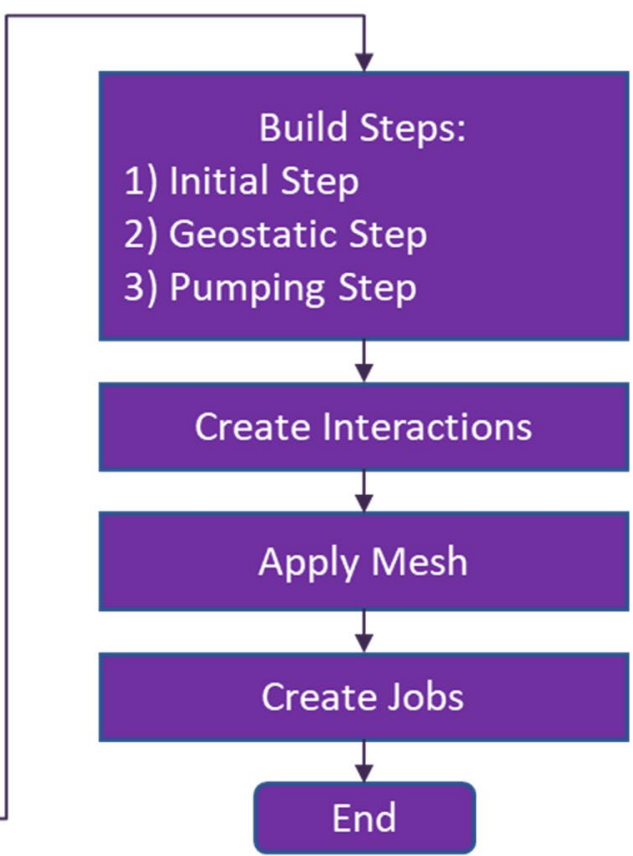

where $K_{\mathrm{I}}^{\mathrm{XFEM}}$ is the mode I stress intensity factor for XFEM and $I_{\mathrm{I}}^{\text {int }}$ is the interaction state for mode $\mathrm{I}$ fracture propagation in XFEM.

$K_{\mathrm{II}}^{\mathrm{XFEM}}=\frac{I_{\mathrm{II}}^{\mathrm{int}} E_{\mathrm{eff}}}{2}$

where $K_{\mathrm{II}}^{\mathrm{XFEM}}$ is the mode II stress intensity factor for XFEM and $I_{\mathrm{II}}^{\mathrm{int}}$ is the interaction state for mode II fracture propagation in XFEM.

The assumption present in the derivation of Eqs. 18 and 19 are that the auxiliary SIFs are exhibiting no effect on SIFs computed.

\section{XFEM modelling in abaqus: general steps}

The main steps in modelling the XFEM is shown by Fig. 6 . There will be a few assumptions done prior to building the model. The assumptions are:

(i) Fracturing fluid is incompressible.

(ii) Fracturing fluid is assumed to be liquid base and not foam base.

(iii) Proppant will not be simulated.

The creation of XFEM model begin with the creation of geometry. The geometry of the formation and existing fractures are created at the part section. The geometry is drawn initially at $2 \mathrm{D}$ and then extruded to form the $3 \mathrm{D}$ object. The fractured formation and existing fracture are defined at this stage. There will be SRV and Non-SRV region in the model.
At the assign properties section the physical properties of the formation and fracture are introduced. The formation is defined by its mechanical properties such as density, Young's modulus, Poison's ratio, porosity, permeability and damage criteria. Each part will have different properties and will be named accordingly. Following that, section is created. Section is the set which contains one of the materials later to be used for the assignation of the materials to the respective part. The model is then assembled. Within assembly, all the parts are combined to produce single system where all constituents will be simulated. After assembling the model, three steps, namely initial step, geostatic step and pumping step need to be created. In the initial step, initial and boundary and conditions will be applied. The initial condition refers to the formation properties such as saturation, stresses and pore pressure. The boundary conditions refers to the symmetry, restriction of displacement and rotation over certain coordinates. In the geostatic step, loads and geomechanical properties are introduced onto the formation. In the pumping step, the injection of the fracturing fluid is defined. Following pumping step, interaction between the components of the system is then introduced. The fracture surface and propagation algorithm are defined within this step. This stage also includes the introduction of the functions to define the enrichment nodes within the simulation. The nodes to be enriched are identified based on LSF and stress intensity factor (SIF). Meshing is then applied on the model. Mesh is the gridding which discretizes the whole part into sub-segments which will be computed separately later. There are several mesh types available within the software, hex, hex-dominated, tet and wedge. For the simulation of 
the FEM tet type of mesh must be selected as it the mesh compatible with remeshing rule. However, for XFEM hex type mesh can be implemented. Hex type mesh produced lesser number of elements for the same geometry than tet. Lastly, job file is created. At this section, simulation is initiated by including required input data which was defined in previous sections. Within this section, user defines the step size and step number to be simulated if required to differ from default values.

In summary, a review has been made on hydraulic fracturing modelling through analytical and numerical method. The basic theory of the methods was presented and comparison are made between the strength and weaknesses based on published studies. Analytical method can be classified into 2D modelling and 3D modelling. Two-dimensional modelling has an advantage of obtaining fast solution due to its simplistic calculation, but it is limited to model constant fracture height. This limitation is removed under 3D modelling; however, it come at the expenses of longer computational time due to higher complexity. Numerical method can be classified as continuum modelling and discontinuum modelling, and under it, XFEM has the greatest advantage in simulating hydraulic fracturing. The significance of XFEM is its ability to simulate arbitrarily propagating fracture, whereas other methods require the fracture trajectory to be pre-defined. This paper has included general steps to create XFEM model for the purpose of simulating hydraulic fracturing.

Acknowledgements The authors would like to thank Universiti Teknologi PETRONAS for their support and approval in publishing this work. This research did not receive any specific grant from funding agencies in the public, commercial, or not-for-profit sectors.

\section{Compliance with ethical standards}

Conflict of interest The authors declare no conflict of interest.

Open Access This article is licensed under a Creative Commons Attribution 4.0 International License, which permits use, sharing, adaptation, distribution and reproduction in any medium or format, as long as you give appropriate credit to the original author(s) and the source, provide a link to the Creative Commons licence, and indicate if changes were made. The images or other third party material in this article are included in the article's Creative Commons licence, unless indicated otherwise in a credit line to the material. If material is not included in the article's Creative Commons licence and your intended use is not permitted by statutory regulation or exceeds the permitted use, you will need to obtain permission directly from the copyright holder. To view a copy of this licence, visit http://creativecommons.org/licenses/by/4.0/.

\section{References}

Abdelfattah MH, Abdelalim AM, Yassin MHA (2015) Unconventional reservoir: definitions, types and Egypt's potential. https://doi. org/10.13140/RG.2.1.3846.0880
Abe H, Keer L, Mura T (1976) Growth rate of a penny-shaped crack in hydraulic fracturing of rocks, 2. J Geophys Res Solid Earth 81(35):6292-6298. https://doi.org/10.1029/JB081i029p05335

Adams J, Rowe C (2013) Differentiating applications of hydraulic fracturing. In: ISRM international conference for effective and sustainable hydraulic fracturing, Brisbane, Australia. http://dx.doi. org/10.5772/56114

Aguilera RF, Radetzki M (2014) The shale revolution: global gas and oil markets under transformation. Mineral Econ 26:75-84. https ://doi.org/10.1007/s13563-013-0042-4

Aguilera RF, Ripple RD (2012) Link between rocks, hydraulic fracturing, economics, environment, and the global gas portfolio. In: SPE Canadian unconventional resources conference, Calgary, Alverta, Canada. https://doi.org/10.2118/162717-MS

Arndt S, Van der Zee W, Hoeink T, Nie J (2015) Hydraulic fracturing simulation for fracture networks. In: Simulia community conference, Berlin. https://pdfs.semanticscholar.org/a083/e5de0ba924 b50f586244632d86c4395469c1.pdf?_ga $=2.58988013 .11538$ 11318.1590043751-1948269119.1590043751

Barbier E (2002) Geothermal energy technology and current status: and overview. Renew Sustain Energy Rev 6:3-65. https://doi. org/10.1016/S1364-0321(02)00002-3

Bataille A, Genthon P, Rabinowicz M, Fritz B (2006) Modeling the coupling between free and forced convection in a vertical permeable slot: implications for the heat production of an enhanced geothermal system. Geothermics 35:654-682. https ://doi.org/10.1016/j.geothermics.2006.11.008

Bentley RW (2002) Global oil \& gas depletion: an overview. Energy Policy 30:189-205. https://doi.org/10.1016/S0301 $-4215(01) 00144-6$

Bordas SPA, Moran B (2006) Enriched finite elements and level sets for damage tolerance assessment of complex structures. Eng Fract Mech 73(9):1176-1201. https://doi.org/10.1016/j.engfr acmech.2006.01.006

Britt L (2012) Fracture stimulation fundamentals. J Nat Gas Sci Eng 8:34-51. https://doi.org/10.1016/j.jngse.2012.06.006

Costabel M (1987) Principles of boundary element methods. In: Computer Physics Reports (eds) Computer Physics Reports, vol 6(1-6). Elsevier, Amsterdam, pp. 243-274. https://doi. org/10.1016/0167-7977(87)90014-1

Eklind M, Ericsson P, Jonsson J, Lewen M, Nord G, Samuelsson B, Potts A, Casteel K, Ericsson M (2007) Mining methods in underground mining, 2nd edn. Atlas Copco Rock Drills AB, Orebro. https://miningandblasting.files.wordpress.com/2009/09/ mining_methods_underground_mining.pdf

Feng Y, Gray K (2017) Modeling near-wellbore hydraulic fracture complexity using coupled pore pressure extended finite element method. In: The 51st US rock mechanics/geomechanics symposium, San Fransisco, California, USA. https://www.onepetro. org/conference-paper/ARMA-2017-0352

Fu P, Settgast RR, Hao Y, Morris JP, Ryerson FJ (2017) The influence of hydraulic fracturing on carbon storage performance. J Geophys Res Solid Earth 122:9931-9949. https://doi. org/10.1002/2017JB014942

Gates ID (2011) Basic reservoir engineering, 1st edn. Kendall-Hunt, Dubuque

GEA (2016) Annual U.S. global geothermal power production report, Geothermal Energy Association (GEA). https://www. eesi.org/files/2016_Annual_US_Global_Geothermal_Power _Production.pdf

Geertsma J, De Klerk F (1969) A rapid method of predicting width and extent of hydraulically induced fractures. J Petrol Technol 21(12):1571-571581. https://doi.org/10.2118/2458-PA

Gidley JL (1990) Recent advances in hydraulic fracturing, 12. Society of Petroleum Engineers, United States 
Gordon D (2012) Understanding unconventional oil. Energy and Climate. https://carnegieendowment.org/2012/05/03/understandingunconventional-oil-pub-48007

Grechka V, Mazumdar P, Shapiro SA (2010) Predicting permeability and gas production of hydraulically fractured tight sands from microseismic data. Geophysics 75(1):B1-B10. https://doi. org/10.1190/1.3278724

Haszeldine RS (2009) Carbon capture and storage: how green can black be? Science 325:1647-1652. https://doi.org/10.1126/scien ce. 1172246

He Q, Suorineni F, Oh J (2015) Modeling interaction between natural fractures and hydraulic fractures in block cave mining. American Rock Mechanics Association, San Fransisco, California. https:// www.onepetro.org/conference-paper/ARMA-2015-842

Holditch SA (2006) Tight gas sands. J Petrol Technol 58(06):86-93. https://doi.org/10.2118/103356-MS

Hou MZ, Zhou L (2011) Modelling and optimization of multiple fracturing along horizontal wellbores in tight gas reservoirs, harmonising rock engineering and the environment. Taylor \& Francis Group, London. https://doi.org/10.1201/b11646-249

Hsiao GC (2006) Boundary element methods-an overview. Appl Numer Math 56(10):1356-1369. https://doi.org/10.1016/j.apnum 2006.03.030

Hughes JD (2013) Energy: a reality check on the shale revolution. Nature 494(7437):307-308. https://doi.org/10.1038/494307a

Ignatyev A, Mukminov I, Vikulova E, Pepelyayev R (2011) Multistage hydraulic fracturing in horizontal wells as a method for the effective development of gas-condensate fields in the arctic region. In: SPE arctic and extreme environments conference and exhibition, Moscow, Russia. https://doi.org/10.2118/149925-MS

King G (2012) Hydraulic fracturing 101: what every representative, environmentalist, regulator, reporter, investor, university researcher, neighbor and engineer should know about estimating frac risk and improving frac performance in unconventional gas and oil wells. In: SPE hydraulic 489 fracturing technology conference, The Woodlands, Texas, USA. https://doi.org/10.2118/15259 6-MS

Lee D, Cardiff P, Bryant EC, Manchanda R, Wang H, Sharma MM (2015) A new model for hydraulic fracture growth in unconsolidated sands with plasticity and leak-off. In: SPE annual technical conference and exhibition, Houston, Texas, USA. https://doi. org/10.2118/174818-MS

Lei Q, Latham J-P, Tsang C-F (2017) The use of discrete fracture networks for modelling coupled geomechanical and hydrological behaviour of fractured rocks. Comput Geotech 85:151-176. https ://doi.org/10.1016/j.compgeo.2016.12.024

Li Q, Xing H, Liu J, Liu X (2015) A review on hydraulic fracturing of unconventional reservoir. Petroleum 1(1):8-15. https://doi. org/10.1016/j.petlm.2015.03.008

Lucia FJ, Fogg GE (1990) Geological/stochastic mapping of heterogeneity in a carbonate reservoir. J Petrol Technol 42(10):1298291303. https://doi.org/10.2118/19597-PA

Marina S, Imo-Imo EK, Derek I, Mohamed P, Yong S (2014) Modelling of hydraulic fracturing process by coupled discrete element and fluid dynamic methods. Environ Earth Sci 72(9):3383-3399. https://doi.org/10.1007/s12665-014-3244-3

Martin CD, Chandler NA (1993) Stress heterogeneity and geological structures. Int J Rock Mech Min Sci Geomech Abstr Madison Wisconsin. https://doi.org/10.1016/0148-9062(93)90059-M

Maulianda B (2016) On hydraulic fracturing of tight gas reservoir rock, Degree of Doctor Philosophy, Petroleum Engineering Department, University of Calgary, Calgary, Alberta, Canada. https:// doi.org/10.11575/PRISM/27177

Mayerhofer MJ, Lolon E, Warpinski NR, Cipolla CL, Walser DW, Rightmire CM (2010) What is stimulated reservoir volume?. https ://doi.org/10.2118/119890-PA
McClure MW, Horne RN (2013) Discrete fracture network modeling of hydraulic stimulation: coupling flow and geomechanics. Springer, Berlin. https://doi.org/10.1007/978-3-319-00383-2

MIT (2006) The future of geothermal energy: impact of enhanced geothermal systems (EGS) on the United States in the 21st Century, Massachusetts Institute of Technology. https://www1.eere.energ y.gov/geothermal/pdfs/future_geo_energy.pdf

Nolen-Hoeksema RC, Ruff LJ (2001) Moment tensor inversion of microseisms from the B-sand propped hydrofracture, M-site, Colorado. Tectonophysics 336(1):162-181. https://doi.org/10.1016/ S0040-1951(01)00100-7

Nordgren R (1972) Propagation of a vertical hydraulic fracture. Soc Petrol Eng J 12(04):306-314. https://doi.org/10.2118/3009-PA

Orr FM (2009) Onshore geologic storage of CO2. Science 325:16561658. https://doi.org/10.1126/science. 1175677

Peirce A, Detournay E, Adachi J (2010) colP3D: a MATLAB code for simulating a pseudo-3d hydraulic fracture with equilibrium height growth across stress barriers. https://open.library.ubc.ca/ cIRcle/collections/facultyresearchandpublications/52383/items /1.0079337, 2019

Perkins T, Kern L (1961) Widths of hydraulic fractures. J Petrol Technol 13(09):937-949. https://doi.org/10.2118/89-PA

Postnikov A, Gutman I, Postnikova O, Olenova KY, Khasanov I, Kuznetsov A (2017) Potemkin G (2017) Different-scale investigations of geological heterogeneity of bazhenov formation in terms of hydrocarbon potential evaluation (Russian). Oil Ind J 03:8-11

Rahman M, Rahman M (2010) A Review of Hydraulic Fracture Models and Development of an Improved Pseudo-3D Model for Stimulating Tight Oil/Gas Sand. Energy Sources A Recov Util Environ Effects 32(15):1416-1436. https://doi.org/10.1080/1556703090 3060523

Ruehl C, Giljum J (2011) BP energy outlook 2030. https://www. bp.com/content/dam/bp/business-sites/en/global/corporate/pdfs/ energy-economics/energy-outlook/bp-energy-outlook-2011.pdf

Sepehri J, Soliman MY, Morse SM (2015) Application of extended finite element method to simulate hydraulic fracture propagation from oriented perforations. In: SPE hydraulic fracturing technology conference, The Woodlands, Texas, USA. https://doi. org/10.2118/173342-MS

Settari A, Cleary MP (1984) Three-dimensional simulation of hydraulic fracturing. J Petrol Technol 36(07):1177-171190. https://doi. org/10.2118/10504-PA

Shapiro SA, Huenges E, Borm G (1997) Estimating the crust permeability from fluid-injection-induced seismic emission at the KTB site. Geophys J Int 131(2):F15-F18. https://doi.org/10.1111/ j.1365-246X.1997.tb01215.x

Shapiro S, Dinske C, Rothert E (2006) Hydraulic-fracturing controlled dynamics of microseismic clouds. Geophys Res Lett. https://doi. org/10.1029/2006GL026365

Sieminski A (2014) International energy outlook. Energy Information Administration (EIA). https://www.eia.gov/outlooks/ieo/ pdf/0484(2014).pdf

Simonson E, Abou-Sayed A, Clifton R (1978) Containment of massive hydraulic fractures. Soc Petrol Eng J 18(01):27-32. https://doi. org/10.2118/6089-PA

Sukumar N, Prévost J-H (2003) Modeling quasi-static crack growth with the extended finite element method part I: computer implementation. Int J Solids Struct 40(26):7513-7537. https://doi. org/10.1016/j.ijsolstr.2003.08.002

Van AA, Jeffrey RG (2000) Hydraulic fracturing as a cave inducement technique at Northparkes mine. In: MassMin 2000 proceedings, Brisbane, Australia. https://www.tib.eu/en/search/id/ BLCP\%3ACN048376496/Hydraulic-Fracturing-as-a-Cave-Induc ement-Technique/ 
Vera F, Shadravan A (2015) Stimulated reservoir volume 101: SRV in a Nutshell. In: International petroleum technology conference, Doha, Qatar. https://doi.org/10.2523/IPTC-18413-MS

Vik HS, Salimzadeh S, Nick HM (2018) Heat recovery from multiplefracture enhanced geothermal systems: the effect of thermoelastic fracture interactions. Renew Energy 121:606-622. https://doi. org/10.1016/j.renene.2018.01.039

Warpinski N, Wolhart S (2016) A validation assessment of microseismic monitoring. In: SPE hydraulic fracturing technology conference, The Woodlands, Texas, USA. https://doi.org/10.2118/17915 0 -MS

White M, Fu P, McClure M, Danko G, Elsworth D, Sonnenthal E, Kelkar S, Podgorney R (2017) A suite of benchmark and challenge problems for enhanced geothermal system. Geomech Geophys Geo-Energy Geo-Resour 4:79-117. https://doi.org/10.1007/ s40948-017-0076-0

Xia Y, Plummer M, Mattson E, Podgorney R, Ghassemi A (2017) Design, modeling, and evaluation of a doublet heat extraction model in enhanced geothermal systems. Renew Energy 105:232247. https://doi.org/10.1016/j.renene.2016.12.064

Xiang J (2011) A PKN hydraulic fracture model study and formation permeability determination, Master of Science, Petroleum Engineering Department, Texas A\&M University, Texas, USA. https ://pdfs.semanticscholar.org/056b/efb2296c90e58fcbd7ef48ac4 3622a2c71ac.pdf

Warpinski N, Smith MB (1989) Rock mechanics and fracture geometry. In: Recent advances in hydraulic fracturing, SPE monograph, vol 12 , pp 57-80

Yew CH, Weng X (2014) Mechanics of hydraulic fracturing. Gulf Professional Publishing, Houston. https://doi.org/10.1016/C2013 $-0-12927-3$

Youn DJ (2016) Hydro-mechanical coupled simulation of hydraulic fracturing using the extended finite element method (XFEM), Degree of Doctor Philosophy, Engineering-Civil Speciality,
Colorado School of Mines. Arthur Lakes Library, Colorado, USA. http://hdl.handle.net/11124/170324

Youn D, Griffiths D (2014) Hydro-mechanical coupled model of hydraulic fractures using the eXtended finite element method. In: Shale energy engineering 2014: technical challenges, environmental issues, and Public Policy Pittsburgh, Pennsylvania, USA. https ://doi.org/10.1061/9780784413654.024

Yousefzadeh A, Li Q, Aguilera R (2015) Microseismic 101: monitoring and evaluating hydraulic fracturing to improve the efficiency of oil and gas recovery from unconventional reservoirs. In: SPE Latin American and caribbean petroleum engineering conference, Quito, Ecuador. https://doi.org/10.2118/177277-MS

Yousefzadeh A, Li Q, Virues C, Aguilera R (2016) Identification of activated fracture networks using microseismic spatial anomalies, b-values, and magnitude analyses in horn river basin. In: SPE hydraulic fracturing technology conference, The Woodland, Texas, USA. https://doi.org/10.2118/179153-MS

Yousefzadeh A, Li Q, Virues C, Aguilera R (2017) Comparison of PKN, KGD, Pseudo3D, and diffusivity models for hydraulic fracturing of the horn river basin shale gas formations using microseismic data. In: SPE unconventional resources conference, Calgary, Alberta, Canada. https://doi.org/10.2118/185057-MS

Yu G, Aguilera R (2012) 3D analytical modeling of hydraulic fracturing stimulated reservoir volume. In: SPE Latin America and caribbean petroleum engineering conference, Mexico City, Mexico. https://doi.org/10.2118/153486-MS

Zheltov AK (1955) Formation of vertical fractures by means of highly viscous liquid. In: The 4th world petroleum congress, Rome, Italy. https://www.onepetro.org/conference-paper/WPC-6132

Publisher's Note Springer Nature remains neutral with regard to jurisdictional claims in published maps and institutional affiliations. 